\title{
Центральные бактериальные
}

\section{язвы роговицы затяжного течения. Иммунологические аспекты и тактика этиопатогенетического мечения}

В.В. Нероев - член-корр. РАН, А-р мех. наук, профессор, ьиректор

А.А. Катаргина - s-р мед. наук, профессор, заместитель Аиректора по научной работе

^.А. Ковалева - научный сотрудник отьела инфекционных и аммергических заболеваний глаз

Г.И. Кричевская - канд. мед. наук, ведуший научный сотрудник отеела иммунологии и вирусологии

Н.В. Балацкая - кань. биол. наук, начальник отьела иммунологии и вирусологии

И.Г. Куликова - старший научный сотрудник отАела иммунологии и вирусологии

ФГБУ «Московский НИИ глазных болезней им. Гельмгольца» Минздрава России,

105062, Москва, ул. Садовая-Черногрязская, д. 14/19

Цель работы - описать характерные клинические признаки и изучить причины развития неблагоприятного затяжного течения бактериальных язв роговицы (БЯР) центральной локализации, повысить эффективность их лечения. Материал и методы. Обследовано 289 пациентов с центральными БЯР. Выделено 2 типа течения БЯР: благоприятное (острая и подострая формы) и неблагоприятное (затяжная подострая и затяжная хроническая формы). Кровь (122 пробы) и соскобы с язвы роговицы (110 проб) исследовали в гнездовой полимеразной цепной реакции для выявления дезоксирибонуклеиновой кислоты (ДНК) вируса простого герпеса (ВПГ) 1-го, 2-го типов, вируса Эпштейна - Барр, вируса герпеса человека - ВГЧ-6 и ВГЧ-7. Для выявления аутоиммунной сенсибилизации к антигенам роговицы использовали реакцию торможения миграции лейкоцитов периферической крови (215 проб). Результаты. Упациентов с неблагоприятным течением заболевания ДНК ВГЧ в крови и/или роговице обнаружены в 88, 7 \% случаев и только у $10 \%$ - с благоприятным $(p<0,002)$. Увсех пациентов преобладал ВГЧ 6-го типа. Аутосенсибилизация к антигенам роговицы появлялась уже в конце первой - начале второй недели заболевания у 8 (10,4\%) из 77 обследованных больных с благоприятным течением БЯР. При неблагоприятном течении по мере увеличения длительности заболевания отмечалось нарастание числа больных с аутоиммунным компонентом - до 63,2 \% (48 из 76). Включение в общепринятую схему лечения противовирусных и иммуносупрессивных препаратов приводило к полной эпителизации роговицы в течение 5-10 дней. Заключение. Выявлена роль смешанной герпес-бактериальной инфекции и аутоиммунного компонента в патогенезе затяжного характера течения БЯР, что подтверждается эффективностью модифицированной тактики лечения.

Ключевые слова: бактериальные язвы роговицы, вирус простого герпеса, ВЭБ, ВГЧ-6, ВГЧ-7, ПЦР, аутосенсибилизация к антигенам роговицы, РТМЛ.

Для цитирования: Нероев В.В., Катаргина Л.А., Ковалева Л.А., Кричевская Г.И., Балацкая Н.В., Куликова И.Г. Центральные бактериальные язвы роговицы затяжного течения. Иммунологические аспекты и тактика этиопатогенетического лечения. Российский офтальмологический журнал. 2019; 12 (1): 43-9. doi: 10.21516/2072-0076-2019-12-1-43-49

Известно, что бактериальные язвы роговицы (БЯР) - одна из основных причин снижения остроты зрения и роговичной слепоты, они могут приводить К эндофтальмиту, перфорации роговицы и потере глаза [1-7].
БЯР локализуются в любой части роговицы, но более чем у 70 \% больных возникают в центральной зоне, где инфекция протекает тяжелее, труднее поддается лечению, и рубцевание в этой области всегда приводит к потере зрения [2, 7, 8]. 
В острой стадии гнойной язвы роговицы (ЯР) применение общепринятой этиотропной терапии местных и системных антибактериальных препаратов является неоспоримым фактом [9]. По нашим данным, основанным на богатом клиническом опыте, интенсивная своевременная антибактериальная терапия предотвращает бурное разрушение всех слоев роговицы размножающимися возбудителями, а применение метаболических препаратов способствует эпителизации ЯР [2, 9]. До 7-го дня лечения полностью резорбируется гнойный инфильтрат и завершается эпителизация ЯР. Дальнейшая терапия направлена на купирование остаточных воспалительных явлений в строме роговицы и симптомов увеита, который сопровождает бактериальную язву. Общая продолжительность лечения не должна превышать 17 дней [10].

По нашим данным, несмотря на широкий спектр современных местных и системных метаболических препаратов, улучшающих репарацию, в 45,7 \% БЯР, очистившаяся от гнойно-некротических масс, приобретает затяжной, хронический характер течения и представляет большие трудности в лечении.

Известно, что при длительном отсутствии эпителизации ЯР нарушается метаболизм, снижается синтез белка и гликозаминогликанов, повышается активность протеолитических ферментов, что замедляет восстановительные процессы. В результате развиваются дегенеративно-дистрофические процессы, которые могут привести к истончению или перфорации роговицы [11].

По данным разных авторов, с целью восстановления и герметизации дефектов роговицы применяются различные материалы: конъюнктива, роговица, амниотическая мембрана, лечебные мягкие контактные линзы и др. $[12,13]$.

Хирургические методы герметизации дефектов роговицы широко распространены в офтальмологической практике, но они относятся к симптоматическому лечению и не обладают профилактической и этиопатогенетической терапевтической направленностью.

До сих пор недостаточно изучены причины развития затяжного течения БЯР центральной локализации. Недостаточная эффективность диагностики вызывает острую необходимость в использовании более точных и информативных лабораторных методов, позволяющих выявить этиопатогенетические факторы развития затяжного течения БЯР.

Многолетний клинический опыт позволил нам предположить, что БЯР с затяжным течением имеют смешанную герпетическо-бактериальную этиологию, которую нельзя диагностировать по клиническим признакам, так как биомикроскопические клинические проявления соответствуют клинической картине бактериальной язвы [14].

Кроме того, трудности лечения во многом определяются недостаточностью сведений о пато- генезе заболевания, в частности о роли системной аутоиммунной сенсибилизации при центральных инфекционных ЯР. Принято считать, что истинную аутоиммунную природу имеют краевые кератиты и ЯР (язва Мурена и др.) [15, 16].

До настоящего времени вопрос применения кортикостероидов в лечении БЯР является спорным, так как известно, что инстилляции кортикостероидов при центральных инфекционных ЯР могут замедлять процессы эпителизации $[17,18]$. Высказывается мнение, что инстилляции глюкокортикоидов при центральных БЯР необходимы, так как их применение уменьшает воспалительную реакцию и не вызывает побочных эффектов, поэтому многие авторы считают оправданным применение кортикостероидов при ЯР [19, 20].

Таким образом, существует необходимость в дополнительных методах этиопатогенетического исследования и модификации общепринятой тактики лечения, ориентированной на новые звенья этиологии и патогенеза затяжной БЯР. Модифицированная схема терапии должна быть направлена на профилактику возникновения и повышение эффективности лечения уже развившейся затяжной БЯР центральной локализации, на сокращение продолжительности лечения и отсутствие осложнений.

ЦЕЛЬ работы - выявление характерных клинических признаков и изучение причин развития неблагоприятного затяжного течения БЯР центральной локализации, повышение эффективности их лечения.

\section{МАТЕРИАЛ И МЕТОДЫ}

Обследовано 289 пациентов (289 глаз) в возрасте от 18 до 82 лет с БЯР центральной локализации. Длительность заболевания на момент госпитализации у $157(54,3 \%)$ пациентов составляла 2-17 дней, у $132(45,7 \%)$ - от 18 до 180 дней.

Все пациенты проходили стандартное офтальмологическое обследование: сбор анамнеза, визометрия, биомикроскопия, флуоресцеиновая проба, оптическая когерентная томография переднего отдела глаза, тонометрия (пальпаторно), эхография. Бактериоскопическое обследование включало определение возбудителя при микроскопическом исследовании мазков с конъюнктивы; культуральное - посев материала на питательные среды, изучение патогенности и чувствительности микрофлоры.

Традиционную схему обследования мы дополнили двумя исследованиями, направленными на детекцию ДНК вирусов герпеса человека (ВГЧ) и выявление органоспецифической аутосенсибилизации [21, 22].

Кровь (122 пробы) и соскобы с ЯР (110 проб) исследовали в высокочувствительной гнездовой полимеразной цепной реакции (ПЦР) (nested polymerase chain reaction) для обнаружения ДНК вируса простого герпеса (ВПГ1 и ВПГ2), вируса Эпштейна - Барр (ВЭБ), ВГЧ-6 и ВГЧ-7 [14]. 
Для определения аутосенсибилизации к антигенам роговицы использовали реакцию торможения миграции лейкоцитов периферической крови (РТМЛ, 153 пробы), широко применяемую при обследовании больных с различными формами офтальмопатологии в микромодификации [22, 23]. Все исследования выполнялись в стационаре, до начала лечения.

Статистическую обработку результатов проводили с помощью компьютерной программы BIOSTADT, использовали методы $\chi$-квадрат, точный критерий Фишера.

\section{РЕЗУЛЬТАТЫ И ОБСУЖДЕНИЕ}

Нами выявлены характерные клинические признаки центральной БЯР неблагоприятного затяжнного течения, появляющиеся после очищения ЯР от гнойно-некротических масс: ЯР различной формы с плоским, рыхлым, инфильтрированным дном, поверхность чистая с признаками дегенеративно-дистрофических нарушений: края отечные, проминирующие, с ксеротическими изменениями; площадь и глубина ЯР не уменьшаются и могут увеличиваться, могут наблюдаться симптомы увеита.

Как показывает клинический опыт, первые клинические признаки неблагоприятного течения БЯР появляются по завершении острого периода заболевания: ЯР не эпителизируется и переходит в подострую фазу, а при отсутствии дополнительного профилактического медикаментозного лечения принимает неблагоприятный затяжной характер, превысив рекомендованный для лечения срок 17 дней.

Изучая варианты течения, мы классифицировали БЯР по срокам завершения эпителизации.

Классификация БЯР по характеру течения

I. Благоприятное течение.

1. Острая форма - на фоне общепринятой терапии к 7-му дню лечения полностью резорбируется гнойный инфильтрат, и ЯР эпителизируется. Дальнейшее лечение направлено на купирование остаточных воспалительных явлений в строме роговицы и симптомов увеита, который сопровождает БЯР в 74,7 \% случаев.

2. Подострая форма - развивается по завершении острого периода БЯР, когда на фоне общепринятой терапии на 7-й день лечения площадь язвы не уменьшается. В этом случае ЯР приобретает описанные нами характерные клинические признаки, но применение метаболических препаратов улучшает репарацию и выздоровление наступает до 17-го дня лечения.

II. Неблагоприятное течение.

1. Затяжная подострая форма БЯР, сроки эпителизации которой составляют от 18 до 30 дней.

2. Затяжная, хроническая форма БЯР, сроки эпителизации которой превышают 30 дней от начала заболевания.

Анализ результатов исследования ткани роговицы и крови в ПЦР показал, что у пациентов с небла- гоприятным течением заболевания по сравнению с благоприятным частота выявления ДНК ВГЧ в крови повышалась в 4 раза, преобладала ДНКемия ВГЧ 6-го типа: при благоприятном течении геном ВГЧ-6 выявлен у $4(6,7 \%)$ из 60, при неблагоприятном у $17(27,4 \%)$ из 62 обследованных. В последнее время накапливается все больше данных о возможной роли не только ВПГ, но и других ВГЧ, в первую очередь ВГЧ-6, в этиопатогенезе заболеваний роговицы [14, 24-27]. Почти у $10 \%$ (6 из 62) отмечена смешанная ВГЧ-6 и ВГЧ-7 ДНКемия.

ДНК ВГЧ (ВГЧ-6, ВЭБ, ВПГ-1, 2) в роговице при неблагоприятном течении БЯР обнаружены в $38(61,3 \%)$ из 62, при благоприятном - в $2(4,2 \%)$ из 48 образцов, то есть выявлялись в 14,6 раза чаще у пациентов с неблагоприятным течением БЯР $(\mathrm{p}<0,002)$. В целом в крови и/или роговице геномы ВГЧ обнаружены у $55(88,7 \%)$ из 62 обследованных пациентов с неблагоприятным течением БЯР и только у $10 \%$ (6 из 60) с благоприятным (p $<0,002)$.

Сопоставление полученных данных с клиническими признаками позволило нам расценивать БЯР с затяжным течением как смешанные, герпес-бактериальные, выявив роль ВГЧ как одного из факторов в патогенезе затяжного характера течения БЯР.

Аутосенсибилизация к антигенам роговицы появлялась уже в конце первой - начале второй недели заболевания у $8(10,4 \%)$ из 77 обследованных больных с благоприятным течением БЯР. При неблагоприятном течении по мере увеличения длительности заболевания отмечалось нарастание числа больных с аутоиммунным компонентом - до 63,2 \% (48 из 76).

При благоприятном течении БЯР аутоиммунный и/или вирусный компоненты обнаружены только в $10,9 \%$ случаев, при неблагоприятном частота их выявления повышалась до 97,6 \%. По нашему мнению, оба эти фактора способствуют затяжному течению ЯР. В связи с этим мы рекомендуем внести в схему обследования пациентов с БЯР тесты на выявление аутоиммунной сенсибилизации к антигенам роговицы и обнаружение ДНК вирусов группы герпеса в крови и роговице.

Лечение центральных БЯР затяжного течения

Таким образом, в связи с полученными новыми данными мы предлагаем дифференцировать тактику медикаментозной терапии БЯР по двум направлениям: профилактика развития неблагоприятного затяжного течения заболевания у пациентов, поступающих на лечение в остром периоде БЯР, и повышение эффективности лечения больных, госпитализируемых с уже развившейся затяжной БЯР, за счет добавления в общепринятую схему лечения противовирусных и иммуносупрессивных лекарственных препаратов (таблица).

Схема профилактики и лечения БЯР идентична, различие имеется лишь в сроках начала противовирусной терапии. При благоприятном подостром течении БЯР противовирусная терапия назначается 
Таблица. Модификация тактики лечения центральной БЯР затяжного течения Table. Modification of treatment tactics of the protracted central bacterial corneal ulcer

\begin{tabular}{|c|c|c|c|}
\hline $\begin{array}{l}\text { Показатели } \\
\text { Parameters }\end{array}$ & $\begin{array}{c}\text { Профилактика } \\
\text { Preventive treatment }\end{array}$ & \multicolumn{2}{|c|}{$\begin{array}{l}\text { Лечение } \\
\text { Treatment }\end{array}$} \\
\hline \multirow{2}{*}{$\begin{array}{l}\text { Характер течения бактериальной язвы } \\
\text { роговицы } \\
\text { A character of bacterial corneal ulcer course }\end{array}$} & $\begin{array}{l}\text { Благоприятное } \\
\text { Favorable }\end{array}$ & \multicolumn{2}{|c|}{$\begin{array}{l}\text { Неблагоприятное } \\
\text { Unfavorable }\end{array}$} \\
\hline & $\begin{array}{l}\text { Подострое } \\
\text { Subacute }\end{array}$ & $\begin{array}{l}\text { Затяжное подострое } \\
\text { Protracted subacute }\end{array}$ & $\begin{array}{l}\text { Затяжное хроническое } \\
\text { Protracted chronic }\end{array}$ \\
\hline $\begin{array}{l}\text { Отсутствие эпителизации (день лечения) } \\
\text { Absence of epithelialization (day of treatment) }\end{array}$ & $\begin{array}{l}\text { От } 8 \text { до } 17 \text { дней } \\
\text { From } 8 \text { to } 17 \text { days }\end{array}$ & $\begin{array}{l}\text { От } 18 \text { до } 30 \text { дней } \\
\text { From } 18 \text { to } 30 \text { days }\end{array}$ & $\begin{array}{l}>30 \text { дней } \\
>30 \text { days }\end{array}$ \\
\hline $\begin{array}{l}\text { Противовирусная терапия, начало (день } \\
\text { лечения) } \\
\text { Antiviral therapy, the beginning (the day of } \\
\text { treatment) }\end{array}$ & $\begin{array}{c}\text { Местная - с 8-го дня } \\
\text { Системная - с 8-го дня } \\
\text { Local - from } 8 \text { days } \\
\text { Systemic - from } 8 \text { days }\end{array}$ & \multicolumn{2}{|c|}{$\begin{array}{c}\text { Местная - с 1-2-го дня } \\
\text { Системная - с } 1-2 \text {-го дня } \\
\text { Local - from } 1-2 \text { days } \\
\text { Systemic - from } 1-2 \text { days }\end{array}$} \\
\hline $\begin{array}{l}\text { Противовирусная терапия, } \\
\text { продолжительность (количество дней) } \\
\text { Antiviral therapy, duration (number of days) }\end{array}$ & \multicolumn{3}{|c|}{$\begin{array}{c}\text { Местная - 7-10 дней } \\
\text { Системная }-5-10 \text { дней } \\
\text { Local therapy }-7-10 \text { days } \\
\text { Systemic therapy }-5-10 \text { days }\end{array}$} \\
\hline $\begin{array}{l}\text { Иммуносупрессивная терапия, } \\
\text { начало (день лечения) } \\
\text { Immunosuppressive therapy, } \\
\text { the beginning (the day of treatment) }\end{array}$ & \multicolumn{3}{|c|}{$\begin{array}{l}\text { C } 1-2 \text {-го дня } \\
\text { From } 1-2 \text { days }\end{array}$} \\
\hline $\begin{array}{l}\text { Иммуносупрессивная терапия, } \\
\text { продолжительность (количество дней) } \\
\text { Immunosuppressive therapy, } \\
\text { duration (number of days) }\end{array}$ & \multicolumn{3}{|c|}{$\begin{array}{l}\text { До выздоровления, не более } 17 \text { дней } \\
\text { Until the recovery is complete, not more than } 17 \text { days }\end{array}$} \\
\hline $\begin{array}{l}\text { Сроки выздоровления, стационарное } \\
\text { лечение (количество дней) } \\
\text { Duration of recovery, hospital treatment } \\
\text { (number of days) }\end{array}$ & \multicolumn{3}{|c|}{$\begin{array}{c}\text { Не более } 17 \text { дней } \\
\text { No more than } 17 \text { days }\end{array}$} \\
\hline
\end{tabular}

после резорбции гнойного инфильтрата, с 8-го дня лечения, с целью профилактики развития неблагоприятного затяжного течения. При неблагоприятном затяжном течении этиологическая противовирусная терапия применяется с 1-2-го дня лечения.

\section{Противовирусная терапия. Показания.}

1. Выявление ДНК одного или нескольких вирусов группы герпеса в крови или в роговице: местная терапия применяется при обнаружении ДНК ВГЧ как в роговице, так и в крови; системная терапия при обнаружении ДНК ВГЧ в крови.

2. Профилактика реактивации герпетической инфекции при проведении иммуносупрессивной терапии.

3. Офтальмогерпес в анамнезе.

4. Экстраокулярная герпетическая инфекция.

Противопоказания: повышенная чувствительность к препарату или его компонентам.

\section{Схема противовирусной терапии}

I. Местная: 1) интерферон человеческий рекомбинантный альфа-2а, глазные капли - препарат широкого спектра противовирусной активности, иммуномодулирующего, антисептического, противовоспалительного, противоаллергического действия; применяется в инстилляциях, по 1 капле 4 раза в сутки; 2) ацикловир, глазная мазь $3 \%$ - закладывается в конъюнктивальный мешок 3 раза в сутки.

Продолжительность местной противовирусной терапии составляет 5-10 дней, до завершения эпителизации язвы.
II. Системная: валацикловир или ацикловир таблетки: 500, 200 мг; дозировка - 1000 мг в сутки.

Продолжительность системной противовирусной терапии - 5-10 дней.

\section{Иммуносупрессивная терапия}

Иммуносупрессивная терапия применяется нами как в остром периоде - в качестве профилактики, так и в лечении развившейся затяжной БЯР - с первых дней лечения. Показания: выявление системной аутосенсибилизации к антигенам роговицы. Противопоказания: десцеметоцеле или перфорация роговицы; применение кортикостероидов в виде инстилляций глазных капель, субконъюнктивальных и внутривенных инъекций; проведение иммуносупрессивной терапии в амбулаторных условиях; повышенная чувствительность к препарату или его компонентам.

\section{Схема иммуносупрессивной терапии}

Для уменьшения рисков, связанных с инстилляциями кортикостероидов, в качестве иммуносупрессивного и противовоспалительного средства мы применяем раствор дексаметазона для инъекций (1 мл, 4 мг), который вводим парабульбарно, ежедневно один раз в сутки в условиях офтальмологического стационара под прикрытием местной противовирусной терапии и ежедневным контролем глубины язвы, при изменении которой индивидуальная дозировка дексаметазона меняется в соответствии со схемой расчета дозы препарата. 
При глубине язвы до 1/3 толщины стромы роговицы вводят по 1,2 мг дексаметазона в объеме 0,3 мл. При глубине язвы 1/3-2/3 толщины стромы роговицы вводят по 0,8 мг дексаметазона в объеме 0,2 мл. При глубине язвы более $2 / 3$ толщины стромы роговицы на фоне отсутствия десцеметоцеле вводят по 0,4 мг дексаметазона в объеме 0,1 мл. В остром периоде БЯР дексаметазон вводится парабульбарно одновременно с раствором антибактериального препарата в течение $3-5$ дней до полной резорбции гнойного инфильтрата и очищения поверхности язвы от гнойно-некротических масс. При явлениях увеита после эпителизации язвы проводят дополнительные ежедневные парабульбарные инъекции дексаметазона по 1,2 мг в объеме 0,3 мл до полного исчезновения явлений увеита.

При глубине язвы более $2 / 3$ стромы, при отсутствии десцеметоцеле, возможна попытка консервативной терапии. Отсутствие эффекта от консервативного лечения в течение 14 дней является показанием для хирургического лечения.

Опираясь на богатый клинический опыт, мы считаем, что при отсутствии возможности проведения обследования или при отрицательных результатах исследования целесообразно назначать иммуносупрессивную терапию при наличии клинических признаков затяжной БЯР под прикрытием местной противовирусной терапии как профилактики реактивации герпетической инфекции.

\section{Хирургическое лечение}

Предлагаемая нами тактика лечения не исключает хирургического вмешательства. Показания: десцеметоцеле или перфорации роговицы; прогрессирующее затяжное течение заболевания с глубиной язвы $2 / 3$ толщины стромы и более; отсутствие эффекта от консервативной терапии в течение 14 дней; непереносимость лекарственных препаратов.

Таким образом, выявлена роль ВГЧ и аутоиммунного компонента в патогенезе затяжного течения БЯР. Включение в общепринятую схему лечения противовирусных и иммуносупрессивных препаратов приводит к полной эпителизации роговицы в течение 5-10 дней в зависимости от степени тяжести и независимо от длительности заболевания. Исследование показало, что применение иммуносупрессивной и противовоспалительной терапии позволило в короткие сроки достичь эпителизации ЯР, а также сократить сроки выздоровления за счет раннего купирования симптомов увеита.

Полученные клинические результаты свидетельствуют об эффективности модифицированного лечения, при котором побочных явлений и перфорации роговицы не отмечалось, лечебные контактные линзы и хирургические методы лечения не применялись. Средняя продолжительность лечения БЯР затяжного течения составила 14,6 койко-дня.

\section{ЗАКЛЮЧЕНИЕ}

На основании многолетнего клинического опыта и результатов лабораторных исследований мы пришли к заключению, что возможными причинами затяжного течения центральных БЯР являются: развитие системной аутосенсибилизации к антигенам роговицы и наличие смешанной герпес-бактериальной инфекции.

Корректировка тактики терапии позволяет предупредить развитие затяжного характера течения БЯР, сократить сроки лечения и избежать возникновения осложнений и необходимости хирургического лечения.

\section{Конфликт интересов: отсутствует.}

Прозрачность финансовой деятельности: никто из авторов не имеет финансовой заинтересованности в представленных материалах или методах.

\section{Лuтература}

1. Майчук Ю.Ф. Терапевтические алгоритмы при инфекционных язвах роговицы. Вестник офтальмологии. 2000; 3: 35-7.

2. Майчук Ю.Ф., Кононенко Л.А. Антибиотики фторхинолоны в лечении язвы роговицы, вызванной синегнойной палочкой при ношении контактных линз. Рефракционная хирургия и офтальмология. 2003; 3 (1): 55-60.

3. Каспарова Е.А. Гнойные язвы роговицы: клиника, диагностика, консервативное лечение. Вестник офтальмологии. 2015; 6: 106-19. doi: 10.17116/oftalma20151316106-119

4. Шаимова В.А. Клинико-этиологические особенности различных типов течения гнойной язвы роговицы. Вестник офтальмологии. 2002; 1: 39-41.

5. Bourcier T., Thomas F., Borderie V., Chaumeil C., Laroche L. Bacterial keratitis: predisposing factors: clinical and microbiological review of 300 cases. Br. J. Ophthalmol. 2003; 87 (7): 834-8. doi: 10.1136/bjo.87.7.834

6. Nurozler A.B. Results of therapeutic penetrating keratoplasty. Jpn. J. Ophthalmol. 2004; 48 (4): 368-71. doi: 10.1007/s10384-004-0083-x

7. Scott I.U., Flynn H.W., Feuer W., et al. Endophthalmitis associated with microbial keratitis. Ophthalmology.1996; 103 (11): 1864-70. doi: http://dx.doi.org/10.1016/S0161-6420(96)30415-6

8. Кононенко Л.А., Майчук Ю.Ф. Эффективность колбиоцина в виде глазной мази и капель в лечении бактериальных кератитов и язв роговицы. Рефракционная хирургия и офтальмология. 2004; 4 (3): 39-42.

9. Ковалева Л.А., Вахова Е.С. Алгоритмы фармакотерапии бактериальных язв роговицы. Эффективная фармакотерапия. 2013; 23: 46-8

10. Майчук Ю.Ф., Кононенко Л.А. Синегнойная язва роговицы: эффективность глазных капель ломефлоксацина - Лофокс Офтальмология Восточная Европа. 2012; 1: 100-6.

11. Макаров П.В., Кугушева А.Э., Ченцова Е.В., Слепова О.С. О персистирующих эрозиях роговичного трансплантата Российский офтальмологический журнал. 2015; 8 (1): 13-8.

12. Пучковская Н.А. Лечебная кератопластика и возможности стимуляции регенеративной способности роговой оболочки. Офтальмологический журнал. 1983; 2: 69-71.

13. Оганесян О.Г., Гундорова Р.А., Майчук Ю.Ф. и др. Новая модификация аутоконъюнктивальной пластики в неотложной хирургии роговицы. Вестник офтальмологии. 2002; 1: 18-22.

14. Нероев В.В., Слепова О.С., Ковалева Л.А., Кричевская Г.И. Оптимизация этиологической диагностики и повышение эффективности лечения инфекционных язв роговицы центральной локализации. Российский офтальмологический журнал. 2017; 10 (3): 56-61. doi: 10.21516/2072-0076-2017$10-3-56-61$ 
15. Mondino B.I. Inflammatory diseases of the peripheral cornea. Ophthalmology. 1988; 95 (4): 463-2.

16. Pleyer U., Bergmann L., Krause A., Hartmann C. Autoimmune diseases of the peripheral cornea. Immunopathology, clinical aspects and therapy. Klin. Monbl. Augenheilkd. 1996; 208 (2): $73-81$.

17. Wilhelmus K.R. Indecision about corticosteroids for bacterial keratitis: an evidence-based update. Ophthalmology. 2002; 109 (5): 835-42. doi:10.1016/s0161-6420(02)00963-6

18. Srinivasan M., Lalitha P., Mahalakshmi R., et al. Corticosteroids for bacterial corneal ulcers. Br. J. Ophthalmol. 2009; 93 (2): 198-202. doi: 10.1136/bjo.2008.147298

19. Palioura S., Henry C.R., Amescua G., Alfonso E.C. Role of steroids in the treatment of bacterial keratitis. Clinical Ophthalmology. 2016; 10: 179-86. doi.org/10.2147/OPTH.S80411

20. Srinivasan M., Mascarenhas J., Rajaraman $R$. The steroids for corneal ulcers trial: study design and baseline characteristics. Arch. Ophthalmol. 2012; 130 (2): 143-50. doi:10.1001/ archophthalmol.2011.315

21. Кричевская Г.И., Слепова О.С., Ковалева Л.А. К вопросу о роли вируса Эпштейна - Барр, вирусов герпеса человека 6-го и 7-го типов в этиопатогенезе язв роговицы с торпидным течением. Проблемы медицинской микологии. 2017; 19 (2): 91-2.
22. Ковалева Л.А., Слепова О.С., Куликова И.Г., Миронкова Е.А. Роль аутоиммунного компонента при центральных язвах роговицы. Российский офтальмологический журнал. 2013; $6(2): 29-31$

23. Куликова И.Г., Слепова О.С., Илуридзе С.Л. Модификация тестов, направленных на выявление аутоиммунных реакций при заболеваниях глаз. Российский офтальмологический журнал. 2013; 6 (1): 69-72.

24. Миронкова Е.А., Демкин В.В., Слепова О.С. и др. Диагностика и роль ВГЧ-6-инфекции при кератопластике высокого риска. Российский офтальмологический журнал. 2012; 5 (3): 30-3.

25. Слепова О.С., Светлова Е.В., Ковалева Л.А. идр. Исследования вируса герпеса человека 6-го типа и других герпес-вирусов, вызывающих заболевания глаз, методом полимеразной цепной реакции. Вопросы вирусологии. 2015; 60 (6): 45-8.

26. Okuno T., Hooper L.C., Ursea R., et al. Role of Human herpes virus 6 in corneal inflammation alone or with human herpesviruses. Cornea. 2011; 30 (2): 204-7. doi: 10.1097/ICO.0b013e3181e2e9be

27. Boto-de-los-Bueis A., Romero Gỏmez M.P., del Hierro Zarzuelo A., et al. Recurrent ocular surface inflammation associated with human herpesvirus 6 infection. Eye Contact Lens. 2015; 41 (3): 11-3.

Поступила: 18.05.2018

Central bacterial corneal ulcers of prolonged course. Immunological aspects and tactics of etiopathogenetic treatment
V.V. Neroev - RAS Corresponding member, Dr. Med. Sci., Professor, director
L.A. Katargina - Dr. Med. Sci., Professor, deputy director for science
L.A. Kovaleva - researcher, department of infectious and allergic eye diseases
G.I. Krichevskaya - Cand. Med. Sci., leading researcher, department of immunology and virology
N.V. Balatskaya - Cand. Med. Sci., head of the department of immunology and virology
I.G. Kulikova - senior researcher, department of immunology and virology

Moscow Helmholtz Research Institute of Eye Diseases, 14/19, Sadovaya-Chernogryazskaya St., Moscow,

105062, Russia

ulcer.64@mail.ru

Purpose: to describe the characteristic clinical signs and to study the causes of the development of an unfavorable prolonged course of bacterial corneal ulcers of central localization, and to improve treatment effectiveness. Material and methods. A total of 289 patients with central bacterial corneal ulcers were examined. Two types courses of bacterial corneal ulcer were distinguished: favorable (acute and subacute) and unfavorable (prolonged subacute and prolonged chronic forms). Blood (122 samples) and scrapings from corneal ulcers (110 samples) were examined in a nested polymerase chain reaction (PCR) to detect deoxyribonucleic acid (DNA) of simple herpes virus (HSV) 1 and 2 types, virus Epstein-Barr (VEB), human herpes virus (HHV)-6, and HHV-7. To detect autoimmune sensitization to the corneal antigens, migration inhibition reaction of leukocytes (MIRL, 215 samples) was used. Results. In patients with unfavorable course of the disease, blood and corneal HHV DNA was detected in $88.7 \%$ of cases, while with a favorable course only $10 \%$ of cases showed the presence of HHV DNA $(p<0.002)$. In all patients, HHV type 6 was predominating. Autosensitivity to corneal antigens was detected in $8(10.4 \%)$ out of 77 patients at the end of the first week of the disease, and as the disease progressed, the number of patients with an autoimmune component increased to reach $63.2 \%$ (48 of 76). The inclusion of antiviral and immunosuppressive drugs into the routine treatment plan led to complete epithelialization of the cornea within 5-10 days. Conclusion. The protracted course of bacterial corneal ulcers was found to be caused by a mixed herpes-bacterial infection, which is corroborated by the effectiveness of the modified treatment tactics.

Keywords: bacterial corneal ulcers, simple herpes virus, EBV, HSV, HHV-6, HHV-7, PCR, autosensitization to cornea antigens, MIRL 
For citation: Neroev V.V., Katargina L.A., Kovaleva L.A., Krichevskaya G.I., Balatskaya N.V., Kulikova I.G. Central bacterial corneal ulcers of prolonged course. Immunological aspects and tactics of etiopathogenetic treatment. Russian ophthalmological journal. 2019; 12 (1): 43-9 (In Russian). doi: 10.21516/2072-0076-2019-12$1-43-49$

Conflict of interests: there is no conflict of interests.

Financial disclosure: No author has a financial or property interest in any material or method mentioned.

\section{References}

1. Maychuk Yu.F. Therapeutic algorithms in infectious ulcer of the cornea. Vestnik oftal'mologii. 2000; 3: 35-7 (in Russian).

2. Maychuk Yu.F., Kononenko L.A. Antibiotics fluoroquinolones in the treatment of corneal ulcers provoked by Pseudomonas aeruginosa under contact lens wearing. Refrakcionnaya khirurgiya i oftal'mologiya. 2003; 3 (1): 55-60 (in Russian).

3. Kasparova E.A. Purulent corneal ulcers: clinical presentation, diagnosis, and conservative treatment. Vestnik oftalmologii. 2015; 6: 106-19 (in Russian). doi: 10.17116/oftalma20151316106-119

4. Shaimova V.A. Clinico-etiological features of different types of course of purulent corneal ulcer. Vestnik oftal'mologii. 2002; 1: 39-41 (in Russian).

5. Bourcier T., Thomas F., Borderie V., Chaumeil C., Laroche L. Bacterial keratitis: predisposing factors: clinical and microbiological review of 300 cases. Br. J. Ophthalmol. 2003; 87 (7): 834-8. doi: 10.1136/bjo.87.7.834

6. Nurozler A.B. Results of therapeutic penetrating keratoplasty. Jpn. J. Ophthalmol. 2004; 48 (4): 368-71. doi: 10.1007/s10384-0040083-X

7. Scott I.U., Flynn H.W., Feuer W., et al. Endophthalmitis associated with microbial keratitis. Ophthalmology.1996; 103 (11): 1864-70. doi: http://dx.doi.org/10.1016/S0161-6420(96)30415-6

8. Kononenko L.A., Maychuk Yu.F. Efficacy of colbiocini eye ointment and eye drops in treatment of bacterial keratitis and corneal ulcers. Refrakcionnaya khirurgiya i oftal'mologiya. 2004; 4 (3): 39-42 (in Russian).

9. Kovaleva L.A., Vakhova E.S. Drug therapy algorithms in bacterial corneal ulcers. Effektivnaya farmakoterapiya. 2013; 23: 46-8 (in Russian).

10. Maychuk Yu.F., Kononenko L.A. Pseudomonas corneal ulcer: the efficiency of eye drops of lomefloxacin - lofox. Oftal'mologiya Vostochnaya Evropa. 2012; 1: 100-6 (in Russian).

11. Makarov P.V., Kugusheva A.E., Chentsova E.V., Slepova O.S. About persistent erosions of the corneal transplant. Russian ophthalmological journal. 2015; 8 (1): 13-8 (in Russian).

12. Puchkovskaya N.A. Therapeutic keratoplasty and the possibilities of stimulating the regenerative capacity of the cornea. Oftal'mologicheskiy zhurnal. 1983; 2: 69-71 (in Russian).

13. Oganesyan O.G., Gundorova R.A., Maychuk Yu.F., et al. A new modification of auto-conjunctival plastics in urgent corneal surgery. Vestnik oftal'mologii. 2002; 1: 18-22 (in Russian).

14. Neroyev V.V., Slepova O.S., Kovaleva L.A., Krichevskaya G.I. Optimization of etiologic diagnosis and improvement of treatment efficiency of corneal infectious ulcers of central localization. Russian ophthalmological journal. 2017; 10 (3): 56-61 (in Russian). doi: $10.21516 / 2072-0076-2017-10-3-56-61$

15. Mondino B.I. Inflammatory diseases of the peripheral cornea. Ophthalmology. 1988; 95 (4): 463-2.

16. Pleyer U., Bergmann L., Krause A., Hartmann C. Autoimmune diseases of the peripheral cornea. Immunopathology, clinical aspects and therapy. Klin. Monbl. Augenheilkd. 1996; 208 (2): 73-81.

17. Wilhelmus K.R. Indecision about corticosteroids for bacterial keratitis: an evidence-based update. Ophthalmology. 2002; 109 (5): 835-42. doi:10.1016/s0161-6420(02)00963-6

18. Srinivasan M., Lalitha P., Mahalakshmi R. et al. Corticosteroids for bacterial corneal ulcers. Br. J. Ophthalmol. 2009; 93 (2): 198-202. doi: 10.1136/bjo.2008.147298

19. Palioura S., Henry C.R., Amescua G., Alfonso E.C. Role of steroids in the treatment of bacterial keratitis. Clinical Ophthalmology. 2016; 10: 179-86. doi.org/10.2147/OPTH.S80411

20. Srinivasan M., Mascarenhas J., Rajaraman R. The steroids for corneal ulcers trial: study design and baseline characteristics. Arch. Ophthalmol. 2012; 130 (2): 143-50. doi:10.1001/archophthalmol.2011.315

21. Krichevskaya G.I., Slepova O.S., Kovaleva L.A. The role of Epstein-Barr virus, human herpes viruses 6 and 7 types in the etiopathogenesis of corneal ulcer with a torpid course. Problemy meditsinskoy mikologii. 2017;19 (2): 91-2 (in Russian).

22. Kovaleva L.A., Slepova O.S., Kulikova I.G., Mironkova E.A. The role of the autoimmune component in central corneal ulcers. Russian ophthalmological journal. 2013; 6 (2): 29-31 (in Russian).

23. Kulikova I.G., Slepova O.S., Iluridze S.L. A Modification of tests identifying autoimmune reactions in eye diseases. Russian ophthalmological journal. 2013; 6 (1): 69-72 (in Russian).

24. Mironkova E.A., Demkin V.V., Slepova O.S., et al. Diagnostics and role of HHV-6 in high-risk keratoplasty. Russian ophthalmological journal. 2012; 5 (3): 30-3 (in Russian).

25. Slepova O.S., Svetlova E.V., Kovaleva L.A., et al. PCR study of the human herpes virus type 6 and other viruses of the herpes group in eye diseases. Voprosy virusologii. 2015; 60 (6): 45-8 (in Russian).

26. Okuno T., Hooper L.C., Ursea R., et al. Role of Human herpes virus 6 in corneal inflammation alone or with human herpesviruses. Cornea. 2011; 30 (2): 204-7. doi: 10.1097/ICO.0b013e3181e2e9be

27. Boto-de-los-Bueis A., Romero Gómez M.P., del Hierro Zarzuelo A., et al. Recurrent ocular surface inflammation associated with human herpesvirus 6 infection. Eye Contact Lens. 2015; 41 (3): 11-3. 